\section{Como se tornar sociólogo: itinerários na sociologia brasileira}

Elide Rugai BASTOS, Fernando ABRUCIO, Maria Rita LOUREIRO \& José Marcio REGO. Conversas com sociólogos brasileiros. São Paulo, Editora 34, 2006. 464 páginas.

\section{Nísia Trindade Lima}

Ponto de encontro de diferentes tradições intelectuais, a institucionalização universitária da sociologia é o tema privilegiado nos depoimentos de 21 sociólogos convocados a darem seu testemunho e a refletirem sobre o que se revela na quase totalidade dos casos como dupla vocação: a ciência e a política. Em foco, o progressivo processo de especialização, com a delimitação de fronteiras disciplinares entre a sociologia, a ciência política e a antropologia. Ainda que a primeira experiência de ensino de pós-graduação, sugestivamente reunindo antropologia e sociologia em um único programa, tenha ocorrido na Escola Livre de Sociologia e Política, na década de 1940, a institucionalização de um sistema de pós-graduação nos moldes atualmente conhecidos só viria a ocorrer nos anos de 1970, processo amplamente discutido em Conversas com sociólogos brasileiros.

Como estudo de trajetórias intelectuais, os depoimentos têm, entre outros, o mérito de revelar a inconsistência de se pensar em projetos pessoais definidos a priori. As diferentes narrativas sobre as carreiras individuais dos sociólogos entrevistados não se apresentam, assim, como construção teleológica, voltada a identificar um objetivo que modelaria retrospectivamente suas escolhas e estilos. Problemas políticos como os que decorreram da implantação do regime militar, oportunidades referidas a projetos de pesquisa que tiveram forte impacto na institucionalização das ciências sociais, e da sociologia em particular, mas também acasos e contingências são lembrados, permitindo perceber um diversificado mosaico, no qual padrões e estilos tanto individuais, mas principalmente institucionais, podem ser identificados.

Como observam os organizadores, os estudos sobre a história das ciências sociais incluem, no Brasil, aqueles que se dedicam à formação do pensamento social e valorizam os autores e as matrizes de interpretação; ao processo de institucionalização das ciências sociais; às relações entre os membros dos grupos que se dedicam à atividade intelectual; à análise de autores específicos; e aos itinerários intelectuais. Para os estudiosos que se situam em qualquer uma dessas vertentes, bem como para um público mais amplo interessado em conhecer a história das ciências sociais, Conversas com sociólogos brasileiros constitui-se em importante referência. O livro vem se somar, desse modo, a uma produção bibliográfica bastante significativa e que consiste em um dos temas privilegiados no Grupo de Trabalho "Pensamento Social Brasileiro" da Anpocs (Miceli, 1989; Santos, 2002; Oliveira, 1999; Villas Bôas, 2006).

De acordo com seus organizadores, o livro apresenta uma síntese da história da sociologia no Brasil, na perspectiva dos participantes deste processo. Entretanto, um ponto a ser observado é que ele representa algumas versões sobre essa história, condicionadas pela experiência em um conjunto restrito de instituições, tanto no que se refere à atualidade, como principalmente no que se refere às gerações que iniciaram suas carreiras no período entre 1940 e 1960. Refiro-me especificamente ao problema do universo dos sociólogos entrevistados para o projeto, comentado na apresentação: "predominaram na montagem da lista os sociólogos ligados de alguma forma à Universidade de São Paulo, seja pela formação, seja pelo trabalho profissional atual ou passado" (p. 9). Ainda que se concorde com os organizadores quanto ao lugar de destaque ocupado pela USP e que se entendam as dificuldades para o registro de todos os depoimentos previstos no projeto original, cabe ressaltar o viés presente na publicação.

De fato, em um total de 21 depoentes, onze tiveram ou mantém vínculos como docentes da Universidade de São Paulo: Florestan Fernandes, Octavio Ianni, Fernando Henrique Cardoso, Juarez Brandão Lopes, Gabriel Cohn, José de Souza Martins, Sergio Miceli, Brasilio Sallum Jr., Reginaldo Prandi, Maria Arminda do N. Arruda e Ricardo Abramovay. O quadro de depoentes é completado pelos sociólogos que pertencem aos quadros docentes da Universidade de Campinas (Unicamp) Renato Ortiz e Ricardo Antunes - por José Carlos 
Durand, aposentado pela Fundação Getulio Vargas-SP e pesquisador associado ao grupo Focus, da Faculdade de Educação da Unicamp; Benicio Viero Schmidt, da Universidade de Brasília (UnB); Elisa Reis e Gláucia Villas Bôas, da Universidade Federal do Rio de Janeiro (UFRJ); Ricardo Benzaquen e Luiz Werneck Vianna do Instituto Universitário de Pesquisas do Rio de Janeiro (Iuperj); César Barreira da Universidade Federal do Ceará (UFC) e José Vicente Tavares, da Universidade Federal do Rio Grande do Sul (UFRS).

A maior representatividade uspiana é quase absoluta no que se refere à primeira e à segunda geração de sociólogos entrevistados. Com isto, experiências importantes como as que ocorreram na Escola Livre de Sociologia e Política, no Instituto Superior de Estudos Brasileiros, no Centro Brasileiro de Pesquisas Educacionais, no Centro LatinoAmericano de Pesquisas em Ciências Sociais e em outras áreas de atuação das ciências sociais são pouco consideradas ou analisadas em larga medida sob o prisma dos que participaram da constituição da sociologia na USP. De todo modo, no que se refere à experiência da Escola Livre de Sociologia e Política, por exemplo, os leitores poderão se beneficiar dos comentários de Florestan Fernandes, que defendeu nessa instituição sua dissertação de mestrado A organização social dos tupinambás, e principalmente do depoimento de Juarez Brandão Lopes, que se estende sobre sua vivência naquela instituição e o contato com alguns professores.

Não obstante essa ponderação, o livro apresenta-se como fonte importante para os estudos sobre a história das ciências sociais. Sua leitura permite elucidar aspectos referidos às orientações teórico-metodológicas predominantes em cada momento, aos meios e aos recursos institucionais que favoreceram a produção acadêmica em certas temáticas e abordagens, e à definição de agendas de pesquisa. Do conjunto de depoimentos, apenas os de Florestan Fernandes e Octavio Ianni não foram realizados tendo em vista esse projeto editorial. O primeiro foi composto a partir da entrevista realizada por Caio Navarro Toledo e publicada em $A$ condição do sociólogo (Hucitec, 1978) e o de Ianni, com base nas entrevistas concedidas pelo autor ao Jornal da Unicamp, à revista Estudos Avançados e de depoimento inédito prestado a Elide Rugai Bastos, uma das organizadoras do livro, em 1983.
Com relação ao período de 1940 a 1964, os depoimentos indicam o esforço de constituir a sociologia como ciência, distinguindo-a da filosofia, como observa Fernando Henrique Cardoso ou, nas palavras de Florestan Fernandes, o esforço de afirmá-la como uma ciência empírica. Ressalte-se também, no que se refere a esse período, a importância de projetos como o de "Relações raciais no Brasil", promovido pela Unesco, bem como do projeto "Economia e sociedade" e da criação do Centro de Sociologia Industrial e do Trabalho (CSIT).

O primeiro teve particular importância em investigações realizadas tanto pelos intelectuais da USP, sob a liderança de Florestan Fernandes, como em diversos outros centros do país. Em seu âmbito, foi firmado o convênio entre a Universidade de Columbia e o governo do estado da Bahia para o desenvolvimento da pesquisa empreendida por Thales de Azevedo, da então Faculdade de Filosofia da Bahia, Charles Wagley, Marvin Harris, Harry William Huntchinson e Benjamin Zimmerman. Também no Rio de Janeiro, sob a coordenação de Costa Pinto, do Departamento de Ciências Sociais da Faculdade Nacional de Filosofia (FNFi), e, em Pernambuco, sob a liderança de René Ribeiro, da Fundação Joaquim Nabuco, o projeto alcançou expressivos resultados (Maio, 1997).

Segundo Florestan Fernandes, a pesquisa sobre Relações raciais foi a maior de que participou e teve como um dos resultados a publicação dos livros que considerava sua maior contribuição empírica ao conhecimento sociológico da sociedade brasileira. Referências a essa investigação, assim como ao projeto "Economia e sociedade" e ao papel do CSIT, podem ser encontradas nos depoimentos de Florestan Fernandes, Octavio Ianni, Fernando Henrique Cardoso, Gabriel Cohn e José de Souza Martins. Neles evidencia-se algo apontado em alguns trabalhos sobre a história das ciências sociais no Brasil: a importância de se problematizar a contraposição entre ciência e política (Martins, 1996). No que se refere à institucionalização da sociologia na USP, trata-se de observar a convivência entre a busca de se moldar uma comunidade científica com os atributos de autonomia acadêmica, tal como definidos por Robert Merton, e um perfil de intelectual cuja atuação pode ser analisada como a de uma intelligentzia, no sentido proposto por Karl Mannheim (Werneck Vianna, 1997; Lima, 1999;Villas Bôas, 2006). 
Um tema fundamental abordado pelos entrevistados consiste no impacto do regime militar, tanto para os que permaneceram no Brasil como para os que foram estudar em universidades européias e norte-americanas. Nota-se que, para a geração que se graduou por volta de 1970, o estudo de pós-graduação no exterior revelou-se estratégia importante em seu processo de formação acadêmica ao mesmo tempo em que contribuiu para a maior diversidade de orientações teóricas e metodológicas.

O papel de algumas instituições privadas na preservação da pesquisa de qualidade e da liberdade acadêmica durante o regime militar é lembrado em muitos depoimentos, que se reportam ao papel desempenhado pelo Iuperj, pelo Centro Brasileiro de Análise e Planejamento (Cebrap) e pela Fundação Getulio Vargas-SP. Durante esse período, uma experiência institucional importante na formação de lideranças acadêmicas nas ciências sociais brasileiras ocorreu na Faculdade de Sociologia e Política da UFMG, tal como pode ser observado na leitura do depoimento de Elisa Reis. Também a solidariedade de alguns intelectuais e as redes de proteção, que tornaram viável a formação acadêmica e a atividade profissional de muitos cientistas sociais no contexto do autoritarismo, são valorizadas pelos entrevistados e abordadas com acurada sensibilidade por Luiz Werneck Vianna.

Outro marco significativo encontra-se na criação dos primeiros cursos de pós-graduação em ciências sociais no Museu Nacional e no Iuperj, no final da década de 1960. Com eles, a delimitação de fronteiras disciplinares entre sociologia, antropologia e ciência política foi tomando contornos mais nítidos. No que se refere ao quadro atual, a existência de trinta programas de pós-graduação em sociologia é um fato realçado no livro e remete também à discussão sobre a menor concentração regional em torno do eixo Rio de Janeiro-São Paulo. A ampliação do número e a regionalização dos programas merecem atenção de diferentes entrevistados, mas encontra-se mais acentuada nos depoimentos de Reginaldo Prandi e César Barreira.

Diante do progressivo processo de especialização, a criação da Anpocs em 1977 e sua conformação interdisciplinar são valorizadas, especialmente nos depoimentos de Reginaldo Prandi e Ricardo Benzaquen de Araújo. O primeiro observa as resistências à criação da Associação, superadas posteriormente como decorrência de seu papel de romper o isolamento entre os programas e fortalecer a área de ciências sociais. O segundo considera que, além de reunir programas de todas as disciplinas das ciências sociais, a feição interdisciplinar da Anpocs é favorecida pela organização dos grupos temáticos, abertos a profissionais de áreas afins. Em sua perspectiva, a própria sociologia pode ser vista tanto sob o prisma da especialização, como por sua característica mais aberta à "inquietude interdisciplinar".

Um dos pontos fortes da obra consiste na abordagem de questões que poderíamos considerar relativas a uma escala microssociológica, em particular as experiências discentes e docentes dos sociólogos, algo pouco explorado nos estudos sobre história das ciências sociais. Problemas didáticos, escolha de temas, orientações dadas aos estudantes, grau de liberdade e hierarquias acadêmicas sucedem-se nos relatos dos entrevistados. Chamam atenção, quanto a esse aspecto, as mudanças geracionais e, em particular, o aprendizado de "como se tornar um sociólogo", em diferentes momentos. Entre outros temas, tem especial interesse o processo de escolha dos objetos das dissertações e teses, descrito com riqueza de detalhes no depoimento de Sergio Miceli.

Nas entrevistas percebem-se também mudanças no que se refere às orientações teóricas. Como acentua Marcelo Ridenti em sua apresentação ao livro, em contraste com o predomínio de visões mais globais e totalizantes dos primeiros tempos, verifica-se atualmente uma maior fragmentação dos objetos, ainda que em quase todos os depoimentos se valorize a tradição da disciplina na interpretação social de mais amplo alcance. Constata-se ainda uma maior diversidade de influências na produção acadêmica contemporânea. Um dado significativo revela-se no índice onomástico: Max Weber, Karl Marx, Pierre Bourdieu e Karl Mannheim são os autores mais citados, considerandose o conjunto das entrevistas. No que se refere aos temas substantivos abordados, merece registro o fato de o debate em torno da mudança social, mais especificamente da modernização da sociedade brasileira, permanecer como uma questão relevante na agenda intelectual contemporânea.

À pergunta sobre a sociologia hoje e seu possível enfraquecimento, há uma resposta recorrente 
sobre a vitalidade da disciplina e a multiplicidade de papéis profissionais a serem desempenhados pelos sociólogos na atualidade. Os depoimentos, além de consistirem em fonte para a história das ciências sociais, trazem-nos inúmeros pontos de reflexão sobre a atividade acadêmica e sua interface com os problemas e os desafios do mundo contemporâneo. Revelam, ainda, como esses sociólogos interpretaram a sociedade brasileira, desde a década de 1940, ao mesmo tempo em que foram partícipes de sua constituição, tanto ao modelarem o debate de idéias sobre seu passado e seu presente, como ao contribuírem para a imaginação social e a definição da agenda política do país.

\section{Bibliografia}

LIMA, Nísia Trindade. (1999), Um sertão chamado Brasil: intelectuais e representação geográfica da identidade nacional. Rio de Janeiro, Iuperj/ Revan.

MARTINS, José de Souza. (1996), "Ciência e política: uma só vocação". Revista Brasileira de Ciências Sociais, ano 11 (30): 15-22.

MAIO, Marcos Chor. (1997), A história do Projeto Unesco: estudos raciais e ciências sociais no Brasil. Tese de doutorado, Rio de Janeiro, Iuperj.

MICELI, Sergio (org.). (1989), História das ciências sociais no Brasil. São Paulo, Revista dos Tribunais.

OLIVEIRA, Lucia Lippi. (1999), "Interpretações sobre o Brasil", in Sergio Miceli (org.), O que ler na ciência social brasileira (1970-1995), São Paulo/Brasília, Sumaré/Capes.

SANTOS, Wanderley Guilherme dos. (2002), "Paradigma e história: a ordem burguesa na imaginação social brasileira", in Roteiro bibliográfico do pensamento político-social brasileiro (1870-1965), Belo Horizonte/Rio de janeiro, Editora da UFMG/Casa de Oswaldo Cruz.
VILLAS-BÔAS, Gláucia. (2006), Mudança provocada: passado e futuro no pensamento sociológico brasileiro. Rio de Janeiro, FGV.

WERNECK VIANNA, Luiz. (1997), A revolução passiva: iberismo e americanismo no Brasil. Rio de Janeiro, Iuperj/ Revan.

\section{NÍSIA TRINDADE LIMA é pesquisadora da Casa de Oswaldo Cruz/Fiocruz e Editora Científica da Editora Fiocruz. E-mail: lima@coc.fiocruz.}

